\title{
Postprandial Gastrointestinal Blood Flow and Oxygen Consumption: Effects of Hypoxemia in Neonatal Piglets
}

\author{
JOANNE S. SZABO, STEVEN R. MAYFIELD, WILLIAM OH, AND BARBARA S. STONESTREET \\ Department of Pediatrics, Women and Infants Hospital of Rhode Island, Providence, Rhode Island 02905 and \\ Brown University Program in Medicine, Providence, Rhode Island 02912
}

\begin{abstract}
The effects of feeding on gastrointestinal (GI) perfusion and oxygen transport in hypoxemic neonates is unknown. We evaluated these effects in unanesthetized, spontaneously breathing newborn piglets by comparing three experimental groups: nine hypoxemic piglets (mean $\mathrm{PaO}_{2} 26$ torr) which were fed with formula, six hypoxemic piglets (mean $\mathrm{PaO}_{2} 27$ torr) which were not fed, and four normoxemic piglets (mean $\mathrm{PaO}_{2} 79$ torr) which were fed and served as controls. The control-fed group exhibited an increase in stomach and small intestinal mucosal-submucosal blood flow within $\mathbf{3 0}$ min following feeding which was significantly greater than that observed in the hypoxemic fed piglets. $\mathrm{GI} \mathrm{O}_{2}$ delivery and $\mathrm{O}_{2}$ uptake rose significantly $(p<0.05)$ following a meal secondary to increases in total GI blood flow. Oxygen extraction was unchanged postprandially in the control group. In the hypoxemic nonfed piglets, total and regional GI blood flow was unaltered during hypoxemia. Reductions in arterial $\mathrm{O}_{2}$ content led to significant decreases in GI $\mathrm{O}_{2}$ delivery. Gastrointestinal oxygen uptake remained stable with a compensatory increase in $\mathrm{GI} \mathrm{O}_{2}$ extraction. In the hypoxemic-fed piglets, hypoxia significantly decreased stomach blood flow and led to unchanged blood flow in the remainder of the GI tract. Significant reductions in arterial $\mathrm{O}_{2}$ content and GI $\mathrm{O}_{2}$ delivery were observed, accompanied by significant increases in $\mathrm{O}_{2}$ extraction. Hypoxemic fed animals did not exhibit the expected increase in $\mathrm{O}_{2}$ uptake to meet postprandial metabolic demands. When the hypoxemic insult was terminated, fed piglets demonstrated significant total and regional GI hyperemia leading to increased GI $\mathrm{O}_{2}$ uptake when compared with hypoxemic nonfed piglets. We conclude that in the presence of hypoxemia, the newborn piglet's GI tract is subject to decreased oxygen availability. In contrast to the fasted GI tract, the fed GI tract exhibits a significant hyperemia following a limited period of severe hypoxemia and an ability to increase oxygen uptake in an attempt to meet the demands of nutrient absorption. Oxygen uptake is not increased to the same extent as in normoxemic fed animals, thus the efficiency of these mechanisms in satisfying the postprandial $\mathrm{O}_{2}$ demand remains to be determined. (Pediatr Res 21: 93-98, 1987)
\end{abstract}

\section{Abbreviations}

GI, gastrointestinal

$\mathrm{HF}$, hypoxemic fed

Received April 29. 1986; accepted September 10, 1986.

Reprint address Barbara S. Stonestreet, Department of Pediatrics, 101 Dudley Street, Providence, RI 02905-2401.

Supported in part by Training Grant 1 T32 HDO7232-03, National Institute of Child Health and Human Development, Bethesda, MD.

\author{
HNF, hypoxemic nonfed \\ CF, control fed \\ Q́GI, GI tissue blood flow \\ $\mathrm{DO}_{2}$, oxygen delivery \\ VัO $\mathrm{O}_{2}$, oxygen consumption \\ $\mathrm{VO}_{2} / \mathrm{DO}_{2}$, oxygen extraction \\ MABP, mean arterial blood pressure \\ A-V, arteriovenous
}

Controversy exists as to the advisability of feeding infants soon after a hypoxic insult. Feeding is generally withheld in neonates during and for variable periods following hypoxemia because of the increased metabolic demand it places on a compromised gastrointestinal tract and an association with the development of necrotizing enterocolitis (1). However, a recent clinical study in preterm infants with oxygen and ventilator requirements has shown that early enteral feedings may prove beneficial and do not increase the incidence of necrotizing enterocolitis (2).

The awake newborn animal meets the postprandial oxidative demands associated with nutrient absorption through enhanced GI oxygen extraction and selective GI hyperemia $(3,4)$. Studies in adult dogs have shown that hyperemia is most pronounced in the mucosal-submucosal layers of the small intestine because of their active involvement in digestion (5-7).

Studies in newborn piglets $(8,9)$ and lambs $(10)$ during hypoxia have shown that when $\mathrm{PaO}_{2} \leq 30$ torr and $\mathrm{CaO}_{2} \leq 6.5 \mathrm{ml} / \mathrm{dl}$, GI blood flow is decreased with corresponding reductions in oxygen delivery and uptake. Results concerning recovery of these parameters following hypoxemia are contradictory $(8,9)$. Therefore, feeding may produce further damage if the intestine cannot meet the increased energy consumption and oxygen demands required by postprandial GI secretion, absorption, and motility.

We hypothesized that severe hypoxemia would blunt the postprandial hyperemia, limit oxygen delivery and uptake in the fed animal, and thereby potentially impair normal digestive functions. We designed this study to evaluate the concurrent effects of hypoxemia and feeding on GI blood flow and oxygen transport in unanesthetized, spontaneously breathing newborn piglets.

\section{MATERIALS AND METHODS}

Animal preparation. Catheters were placed in nineteen $2-$ to 4-day-old piglets, $24 \mathrm{~h}$ prior to the study. Animals were weighed on the morning of surgery. Anesthesia consisted of $70 \%$ nitrous oxide and $1 \%$ local lidocaine. A left ventricular catheter (via left common carotid artery) was placed for microsphere injections; a distal aortic catheter (via a femoral artery) for reference blood sample withdrawal during microsphere injections, arterial blood gas samples, and arterial oxygen contents; a portal venous cath- 
eter (via common umbilical vein) for venous oxygen contents; a femoral artery catheter for continuous heart rate and blood pressure monitoring; and a femoral or jugular venous catheter for blood replacement. Following surgery, the animal was given an intravenous injection of $10 \%$ dextrose $(10 \mathrm{ml} / \mathrm{kg})$ and ampicillin $(100 \mathrm{mg} / \mathrm{kg})$. Catheters were filled with a heparin solution $(1000 \mathrm{U} / \mathrm{ml})$ and secured in a gauze pouch to the animal's back. After the animal had adequately recovered from anesthesia (approximately $3 \mathrm{~h}$ following surgery), it received $30 \mathrm{ml} / \mathrm{kg}$ of a reconstituted milk formula (Land-O-Lakes, Minneapolis, MN) through an orogastric tube. Milk feedings were subsequently given every $3-4 \mathrm{~h}$ until $12-18 \mathrm{~h}$ prior to the study. The milk preparation contained $10 \%$ total fat, $28 \%$ total protein, $0.25 \%$ total fiber, and $4 \%$ total lactose and was similar in composition to natural sow milk. Following termination of orogastric formula feedings, piglets had access to a feeding trough containing $10 \%$ dextrose until $3 \mathrm{~h}$ prior to the study in order to prevent hypoglycemia and dehydration.

Experimental protocol. On the morning of the study, we confirmed that all catheters were patent and the left ventricular catheter was in appropriate position based on its pressure tracing. Piglets were placed in a cage designed to be airtight when a plexiglass plate was secured under the opening grate. A 60 -min adaptation period preceded the beginning of the study.

We studied three groups of unanesthetized, spontaneously breathing newborn piglets. Nine animals were made hypoxemic $\left(\mathrm{PaO}_{2} 18-33\right.$ torr) using a mixture of $6-8 \% \mathrm{O}_{2}, 5 \% \mathrm{CO}_{2}$, and $87-89 \% \mathrm{~N}_{2}$ to maintain the $\mathrm{PaCO}_{2}$ within the normal range. The animals adapted to this level of hypoxemia within a few minutes and remained awake and tachypneic during the hypoxemic period. Hypoxemia was sustained for $45 \mathrm{~min}$, and the animal received artificial sow milk ( $30 \mathrm{ml} / \mathrm{kg}$ body weight) 15 min following the onset of hypoxia. This group was designated as the HF group. These animals were hypoxemic for $45 \mathrm{~min}$ and the last $30 \mathrm{~min}$ of this period represented the hypoxemic-postprandial period. In the second group, six animals were exposed to a similar degree $\left(\mathrm{PaO}_{2} 24-38\right.$ torr) and duration (45 min) of hypoxia, and were HNF. The third group consisted of four animals which remained normoxemic and were fed 15 min into the study period. This last group was designated as CF.

At the beginning of the study, a baseline arterial blood gas and arterial and portal venous oxygen contents were determined and thereafter the first GI blood flow measurement was made. The piglets were then rendered hypoxemic and/or fed with similar measurements obtained at 15,30, 45, 60, and 120 min after the baseline determinations. In both hypoxemic groups, posthypoxemic measurements were obtained at 60 and $120 \mathrm{~min}$, or 15 and $75 \mathrm{~min}$ following the termination of the hypoxemic period. Arterial blood hematocrits and plasma glucose (glucose oxidase method, YSI Model 23A glucose analyzer, Fisher Scientific Co., Yellow Springs, $\mathrm{OH}$ ) were also measured at baseline and 120 min. Arterial blood gas measurements were determined on a Corning 175 Blood Gas Analyzer (Corning Scientific, Medford, MA) and oxygen contents (in duplicate) on a $\mathrm{Lex}-\mathrm{O}_{2}$-Con (Lexington Instruments, Waltham, MA). Animals received a lethal injection of sodium thiamylal following the 120-min measurement.

Blood flow and oxygen transport determinations. We determined blood flow using $15 \pm 5 \mu \mathrm{m}$ diameter microspheres labelled with one of the following radionuclides: ${ }^{46} \mathrm{Sc},{ }^{51} \mathrm{Cr},{ }^{57} \mathrm{Co}$, ${ }_{95} \mathrm{Nb},{ }^{10.3} \mathrm{Ru}$, and ${ }^{113} \mathrm{Sn}$ (New England Nuclear Inc., Boston, MA) (11). Approximately $6 \times 10^{5}$ microspheres, suspended in a $10 \%$ Dextran solution with $0.01 \%$ Tween 80 were continuously agitated and injected into the left ventricular catheter over $30 \mathrm{~s}$. The catheter was then flushed with $2.0 \mathrm{ml}$ of $0.9 \% \mathrm{NaCl}$, and a reference blood sample was withdrawn from the femoral artery catheter beginning $10 \mathrm{~s}$ before the microsphere injection and lasting for $120 \mathrm{~s}$ at a rate of $1.03 \mathrm{ml} / \mathrm{min}$. Heart rate and blood pressure were continuously monitored during the study using a Hewlett-Packard Transducer and Polygraph recorder (7754 A series, Lexington, MA). These variables remained stable during each microsphere injection. Following each GI blood flow measurement, the animal was transfused with an equal volume of young donor pig blood of similar hematocrit.

Catheter placement was verified at necropsy. The stomach, small intestine, and colon were individually identified, removed, gently washed in normal saline, weighed, and fixed in $10 \%$ formaldehyde. The small intestine was further divided into proximal (jejunum) and distal (ileum) segments, then each segment was dissected into submucosa-mucosa and muscularis-serosa using a blunt dissection technique $(4,12)$. This separation technique was used since it overcomes problems associated with microsphere migration between series circulations $(13,14)$. Tissue samples were packed to a $1 \mathrm{~cm}$ height in glass counting vials. Blood and tissue specimens were counted in a well-type $\gamma$ scintillation spectrometer [Canberra 4203 multichannel $\gamma$ pulseheight analyzer (Meriden, CT) connected to a Tracor Analytic model 1185 sample changer (Elk Grove Village, IL)]. Samples were corrected for isotope decay and spillover counts using a Digital PdP-11/34 computer (Digital Equipment, Maynard, MA). All tissue and reference blood samples contained adequate microspheres to ensure blood flow determination accuracy to within 5-10\% (11).

QGI was determined using the following equation: QGI = $(\mathrm{cpm}$ GI tissue/cpm reference blood) $\times$ rate of reference blood withdrawal.

Total GI blood flow and regional blood flows were determined by summation of the appropriate tissue samples. $\mathrm{DO}_{2}, \dot{\mathrm{VO}} 2$, and $\mathrm{VO}_{2} / \mathrm{DO}_{2}$ were computed with the Fick equation:

$$
\begin{gathered}
\mathrm{DO}_{2}=\dot{\mathrm{Q}} \times \mathrm{CaO}_{2} \\
\dot{\mathrm{VO}}_{2}=\dot{\mathrm{Q}} \times\left(\mathrm{CaO}_{2}-\mathrm{CpvO}_{2}\right) \\
\left.\dot{\mathrm{VO}}_{2} / \mathrm{DO}_{2}=\left(\mathrm{CaO}_{2}-\mathrm{CpvO}\right)_{2}\right) / \mathrm{CaO}_{2}
\end{gathered}
$$

where $\dot{Q}$ is blood flow, $\mathrm{CaO}_{2}$ is arterial oxygen content, and $\mathrm{CpvO}_{2}$ is portal venous oxygen content. The validity of $\mathrm{CpvO}_{2}$ to represent GI venous samples has been confirmed previously $(4,15)$. Blood flow was expressed as $\mathrm{ml} \cdot \mathrm{min}^{-1} \cdot 100 \mathrm{~g}^{-1}$ and $\mathrm{DO}_{2}$ and $\mathrm{VO}_{2}$ were expressed as $\mathrm{ml} \mathrm{O}_{2} \cdot \mathrm{min}^{-1} \cdot 100 \mathrm{~g}^{-1}$.

Data analysis. Data analysis within groups was performed using analysis of variance for repeated measures. If a significant statistical difference was found $(p<0.05)$, we used the Dunnett's multiple range T test to compare the means. The Student's $t$ test was used to compare statistical difference between groups. When repeated measurements were compared between groups, the Bonferroni adjustment was used (16).

\section{RESULTS}

The piglets in the three study groups were of similar age, ranging from 2-4 days. Animal weights did not differ and were $1.33 \pm 0.05 \mathrm{~kg}$ in the HF group, $1.34 \pm 0.08 \mathrm{~kg}$ in the HNF group, and $1.17 \pm 0.20 \mathrm{~kg}$ in the CF group. Baseline and 120 min plasma glucose values and arterial hematocrits were not significantly different among the groups.

The heart rate, MABP, and respirations of the three groups of animals are summarized in Table 1 . Heart rates were unchanged in the HF animals throughout the study period. HNF animals increased heart rate significantly at 15 and $30 \mathrm{~min}$, and control fed animals increased heart rate at 15,30 , and 120 minutes ( $p$ $<0.05$ ). MABP in HF animals were significantly elevated at 15 and $60 \mathrm{~min}(p<0.05)$. The baseline mean arterial blood pressures in the HNF animals were significantly lower than in the HF group, accounting for the significant increases in mean arterial pressures in this group at all subsequent time periods. However, these values were within the physiologic range for newborn piglets $(4,8)$. MABP were unchanged following feeding in control animals. Respiratory rates were significantly elevated above baseline during hypoxemia in the HF and HNF animals.

Blood gas values for the three study groups are shown in Table 2. The HF and HNF piglets developed a significant metabolic 
Table 1. Heart rate, $M A B P$, and respiratory rate of newborn piglets (mean $\pm S E M$ )

\begin{tabular}{|c|c|c|c|c|c|c|c|}
\hline & Groups & $0 \mathrm{~min}$ & $15 \mathrm{~min}$ & $30 \mathrm{~min}$ & $45 \mathrm{~min}$ & $60 \mathrm{~min}$ & $120 \mathrm{~min}$ \\
\hline Heart rate (beats/min) & $\begin{array}{l}\text { HF } \\
\text { HNF } \\
\text { CF }\end{array}$ & $\begin{array}{l}189 \pm 17 \\
176 \pm 21 \\
156 \pm 12\end{array}$ & $\begin{array}{l}221 \pm 10 \\
228 \pm 13^{*} \\
204 \pm 17^{*}\end{array}$ & $\begin{array}{l}211 \pm 7 \\
213 \pm 13^{*} \\
211 \pm 8^{*}\end{array}$ & $\begin{array}{l}186 \pm 9 \\
199 \pm 12 \\
184 \pm 12\end{array}$ & $\begin{array}{l}206 \pm 7 \\
199 \pm 12 \\
176 \pm 15\end{array}$ & $\begin{array}{l}207 \pm 7 \\
189 \pm 15 \\
187 \pm 16^{*}\end{array}$ \\
\hline MABP (mm Hg) & $\begin{array}{l}\mathrm{HF} \\
\mathrm{HNF} \\
\mathrm{CF}\end{array}$ & $\begin{array}{l}67 \pm 1 \\
59 \pm 1 \dagger \\
68 \pm 4\end{array}$ & $\begin{array}{l}76 \pm 3^{*} \\
73 \pm 5^{*} \\
74 \pm 5\end{array}$ & $\begin{array}{l}74 \pm 2 \\
74 \pm 5^{*} \\
73 \pm 6\end{array}$ & $\begin{array}{l}74 \pm 3 \\
71 \pm 6^{*} \\
73 \pm 10\end{array}$ & $\begin{array}{l}81 \pm 2^{*} \\
76 \pm 7^{*} \\
76 \pm 7\end{array}$ & $\begin{array}{l}73 \pm 2 \\
79 \pm 4^{*} \\
75 \pm 4\end{array}$ \\
\hline
\end{tabular}

$* p<0.05$ versus baseline.

$+p<0.01$ versus $\mathrm{HF}$.

Table 2. Arterial blood gas values in newborn piglets (mean $\pm S E M$ )

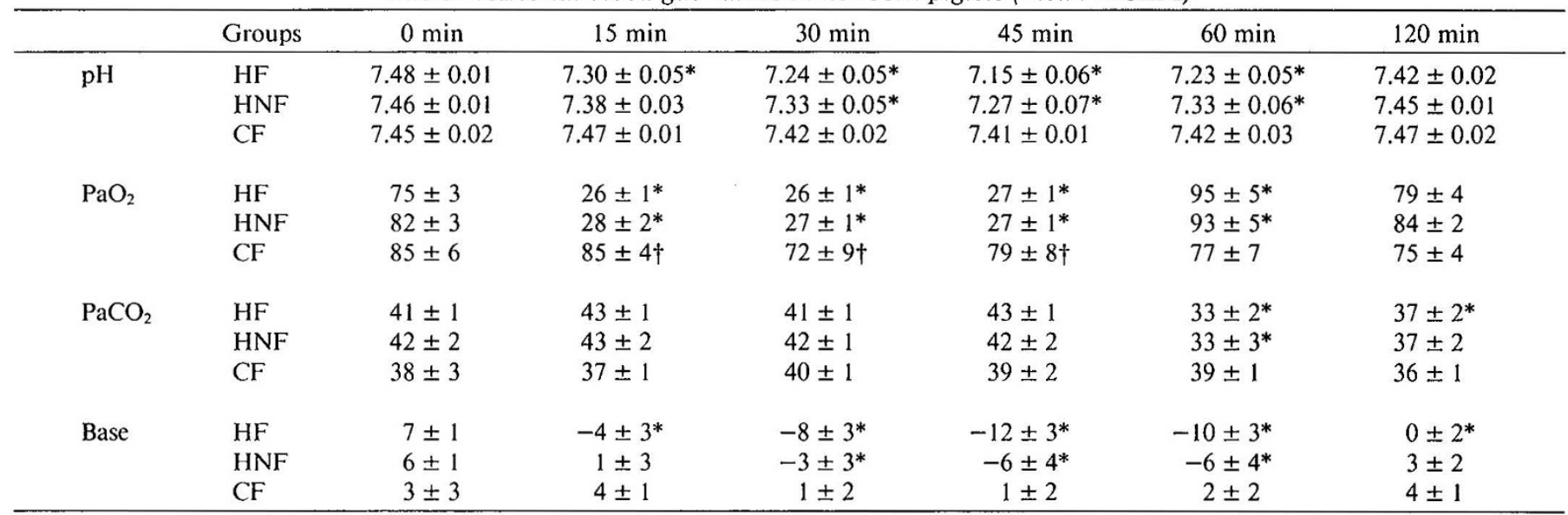

$* p<0.05$ versus baseline.

$\dagger p<0.01$ versus $\mathrm{HF}$.

acidosis at 30-60 min with recovery at $120 \mathrm{~min}$. Arterial $\mathrm{PO}_{2}$ in the $\mathrm{HF}$ and HNF during hypoxemia was significantly lower than corresponding baseline values and the control group values at $15-45 \min (p<0.05)$, and significantly higher than corresponding baseline values at $60 \mathrm{~min}$. Arterial $\mathrm{PCO}_{2}$ values in the $\mathrm{HF}$ and HNF animals were unchanged; however, $\mathrm{PaCO}_{2}$ values decreased during the recovery period in these animals.

Figure 1 summarizes the total GI blood flow and oxygen content values in the three study groups. GI blood flow remained unchanged from the baseline values during the 45-min hypoxemic period in the HF and HNF animals. However, following hypoxemia, the fed piglets exhibited a significant hyperemia. The normoxemic control piglets demonstrated an increase in total GI blood flow following the feeding and the values were significantly higher than in the $\mathrm{HF}$ piglets. Arterial $\mathrm{O}_{2}$ content was significantly decreased from baseline during hypoxemia in $\mathrm{HF}$ and HNF animals and the values were significantly lower than the corresponding values in the $\mathrm{CF}$ group $(p<0.01) . \mathrm{A}-\mathrm{V} \mathrm{O}_{2}$ differences remained unchanged throughout the study and were not significantly different among the three groups (data not shown).

Figure 2 shows that blood flow to the stomach decreased significantly in the HF animals during hypoxemia and rose significantly above baseline values $75 \mathrm{~min}$ after the termination of hypoxemia. Stomach blood flow was unchanged in HNF animals. In the CF piglets, stomach blood flow was significantly higher than in the HF piglets immediately following a meal. As shown in Figure 3, in the HF group a postprandial hyperemia was not evident during the period of hypoxia; however, there

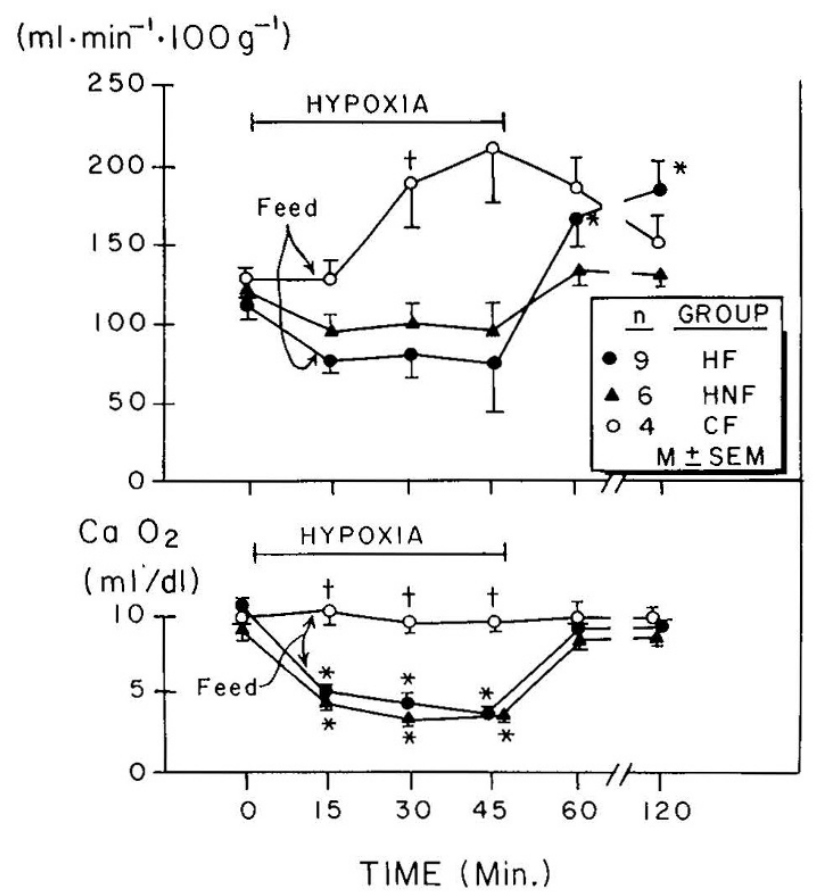

Fig. 1. Total GI blood flow and arterial oxygen content values in the three study groups. ${ }^{*} p<0.05$ versus baseline; $\dagger p<0.01$ versus $\mathrm{HF}$ piglets. 


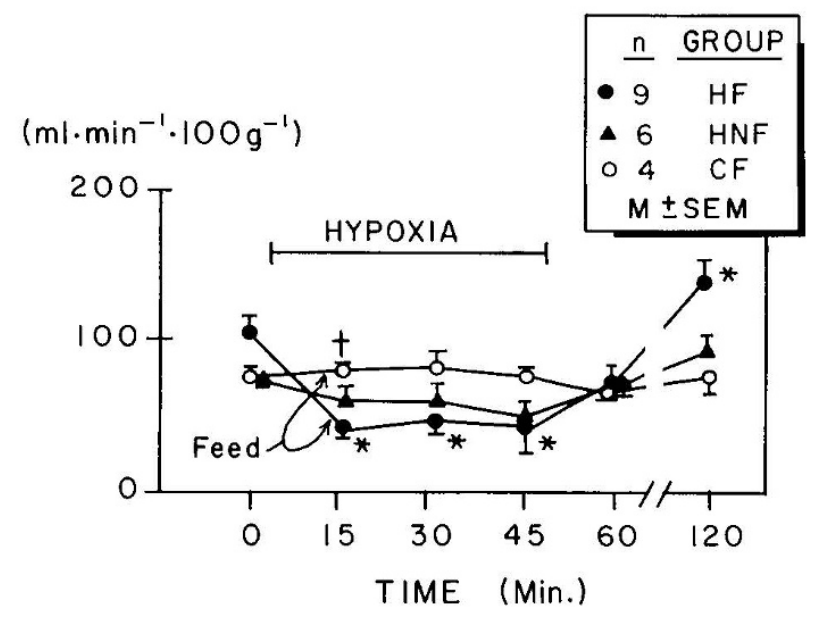

Fig. 2. Stomach blood flow in the three study groups. ${ }^{*} p<0.05$ versus baseline; $\uparrow p<0.01$ versus HF piglets.

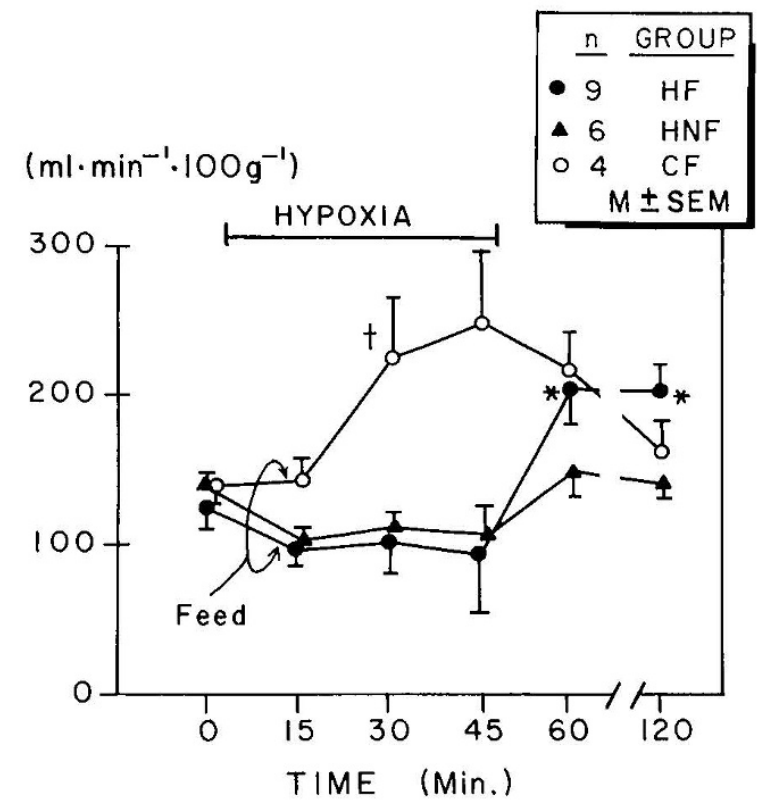

Fig. 3. Small intestinal blood flow in three study groups. ${ }^{*} p<0.05$ versus baseline; $\dagger p<0.01$ versus HF piglets.

was a significant hyperemia following the termination of the hypoxemic period. The HNF group showed no change in small intestinal blood flow throughout the study. In the CF group, the small intestine demonstrated a relative postprandial hyperemia and a return to baseline values at $120 \mathrm{~min}$. Values were significantly higher than HF values following a meal. Figure 4 illustrates blood flow to the colon. In the HF group, blood flow was unchanged until an increase was observed at $120 \mathrm{~min}(p<0.05)$. The HNF and CF animals exhibited no change in colon blood flow throughout the study.

Figures 5 and 6 illustrate the blood flow responses of mucosalsubmucosal and muscularis-serosal layers of the small intestine. In the HF piglets jejunal and ileal mucosal-submucosal blood flow was unchanged during the hypoxemic period, however, demonstrated a significant rise above baseline levels in the posthypoxemic period. HNF animals exhibited no changes in the mucosal-submucosal blood flow during the study. Control fed piglets demonstrated maximal increases in jejunal mucosalsubmocosal blood flow $30 \mathrm{~min}$ following the feeding. Blood flow was significantly higher 15 min postprandial in the jejunum mucosa-submucosa and 15 and $30 \mathrm{~min}$ postprandial in the ileum mucosa-submucosa than the corresponding values in the $\mathrm{HF}$ group $(p<0.01)$. Small intestine mucosa-submucosa blood flow changes accounted for most of the postprandial hyperemic response. Jejunal and ileal muscularis blood flow (Fig. 6) did not contribute to the small intestinal postprandial hyperemia. However, HF piglets did show a significant muscularis hyperemia in the jejunum and ileum at $120 \mathrm{~min}$, which was significantly greater $(p<0.01)$ in the jejunum than the corresponding values in the HNF and CF piglets. HNF and CF piglets exhibited no change in jejunal or ileal muscularis blood flow.

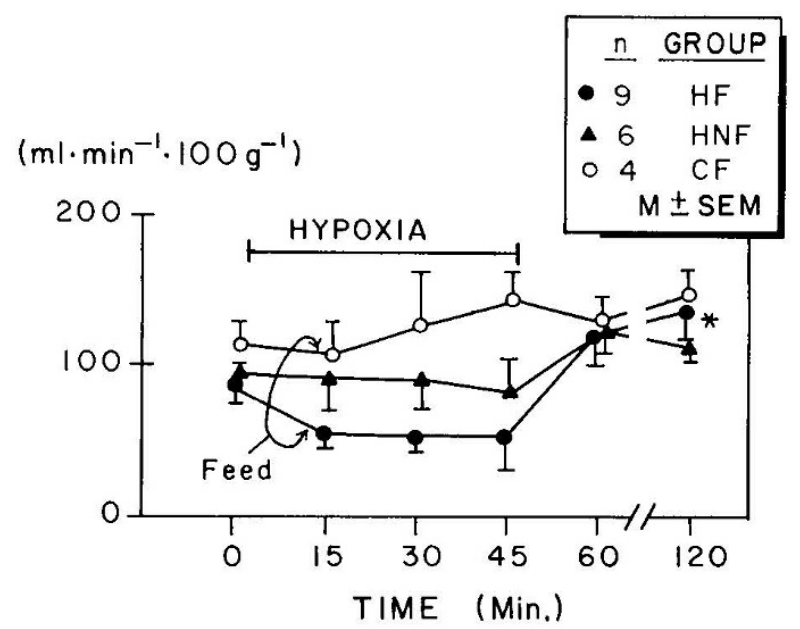

Fig. 4. Colonic blood flow in the three study groups. ${ }^{*} p<0.05$ versus baseline.

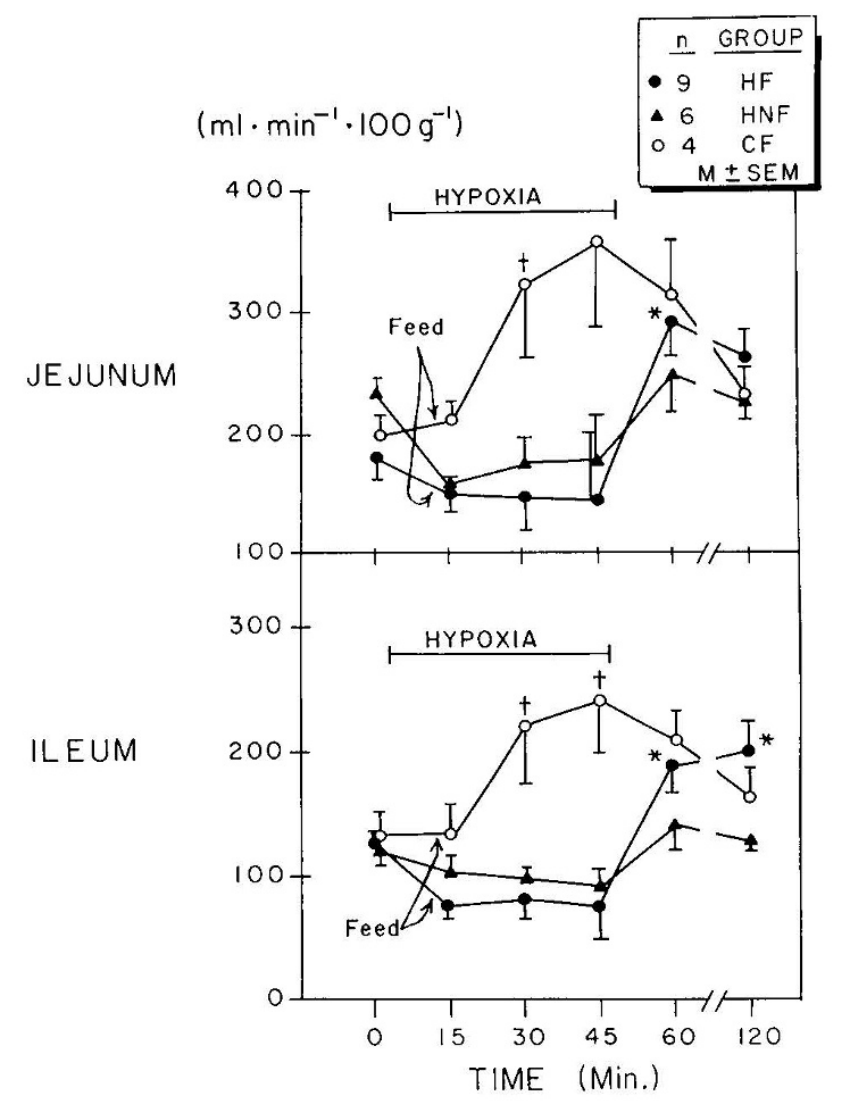

Fig. 5. Jejunal and ileal mucosal-submucosal blood flow in the three study groups. ${ }^{*} p<0.05$ versus baseline; $\uparrow p<0.01$ versus $\mathrm{HF}$ piglets. 


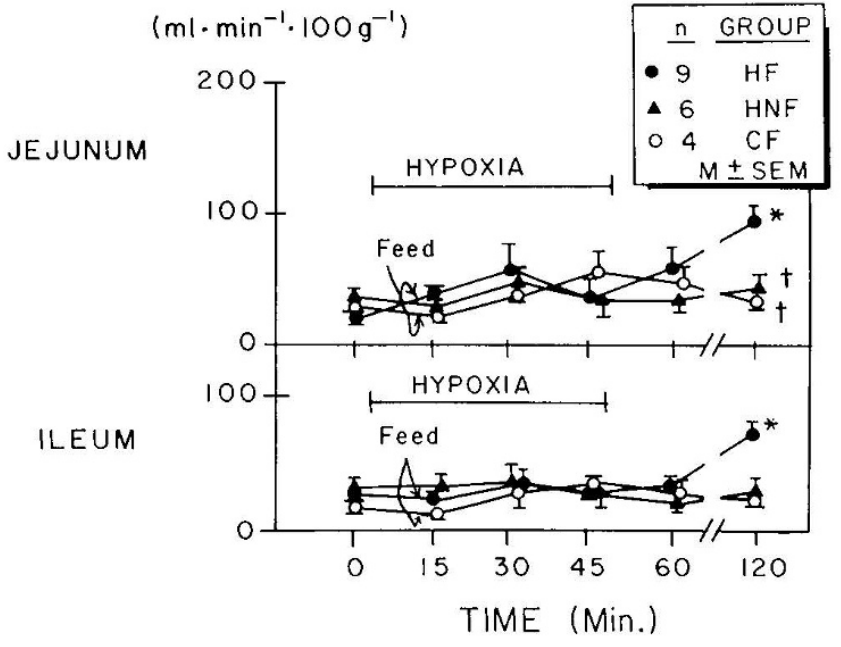

Fig. 6. Jejunal and ileal muscularis-serosal blood flow in the three study groups. ${ }^{*} p<0.05$ versus baseline; $\dagger p<0.01$ versus HF piglets.

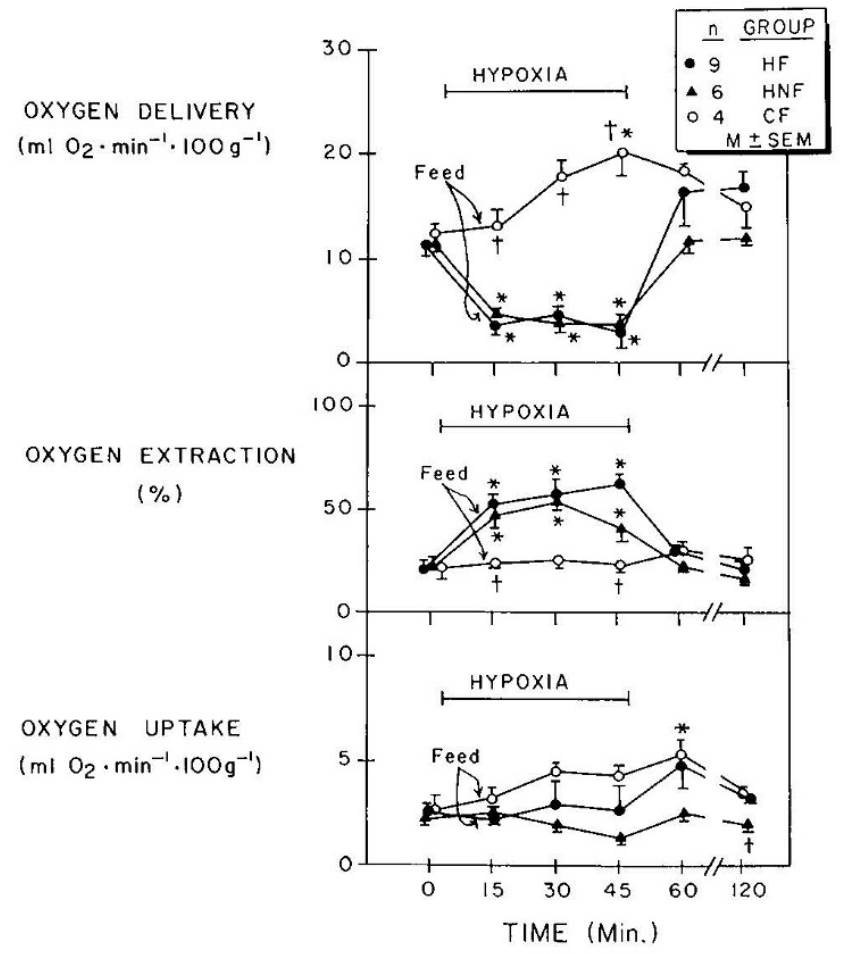

Fig. 7. Total $\mathrm{GI} \mathrm{DO}_{2}, \mathrm{VO}_{2} / \mathrm{DO}_{2}$, and uptake in the three study groups. ${ }^{*} p<0.05$ versus baseline; $\dagger p<0.01$ versus $\mathrm{HF}$ piglets.

The oxygen transport values in the GI tract are illustrated in Figure 7. The CF piglets demonstrated significant increases in $\mathrm{GI} \mathrm{O}_{2}$ delivery at $30 \mathrm{~min}$ following the meal. Significant decreases in $\mathrm{GI}_{2} \mathrm{O}_{2}$ delivery were observed during hypoxemia in the $\mathrm{HF}$ and HNF piglets. The $\mathrm{O}_{2}$ delivery was significantly higher in the $\mathrm{CF}$ than the HF piglets from 15 to 45 min postprandial. Oxygen extraction increased significantly in the $\mathrm{HF}$ and $\mathrm{HNF}$ piglets during the hypoxemic period. The increase in $\mathrm{GI}_{2}$ extraction was significantly greater in the $\mathrm{HF}$ than the CF piglets at 15 and $45 \mathrm{~min}$ following the feeding. $\mathrm{GI} \mathrm{O}_{2}$ uptake was increased significantly at $60 \mathrm{~min}$, or $45 \mathrm{~min}$ postprandial, in the CF piglets. GI $\mathrm{O}_{2}$ uptake remained unchanged in the $\mathrm{HF}$ and $\mathrm{HNF}$ piglets. GI $\mathrm{O}_{2}$ uptake was significantly $(p<0.01)$ higher in the HF than HNF piglets at $120 \mathrm{~min}$.

\section{DISCUSSION}

We examined the effects of feeding on GI perfusion and oxygen transport in hypoxemic neonatal piglets by comparing them with CF piglets (4) and $\mathrm{HNF}$ piglets $(8,9)$.

The baseline heart rates, MABP, and respiratory rates recorded in this study were consistent with those observed in similar animal models $(4,17)$. HF animals did not exhibit a significant degree of tachycardia as seen in the HNF and CF animals. This appears to be due to higher baseline heart rate values $(p>0.05)$ in this group, because heart rates at subsequent time periods were not significantly different among the groups. Elevations in blood pressure in the HF group were presumed to be secondary to catecholamine release caused by the hypoxemic stress. In HNF animals, elevations in heart rate and MABP again occurred presumably because of catecholamine release but potentially from the interaction of a number of variables (18); however, the lower baseline mean arterial blood pressure makes interpretation of the significance of the subsequent rise in blood pressure difficult. The CF piglets increased heart rate significantly in the early postprandial period consistent with a probable sympathomimetic response resulting from the anticipation and ingestion of food $(6,19)$. Blood pressure and respiratory rates were not significantly affected by feeding or digestion (4), as observed by others.

We noted a postprandial increase in GI blood flow in the CF piglets, as observed in adults $(5,6,12,20,21)$ and neonates $(3$, 22) of various species. Our baseline total GI blood flow and 30min postprandial values were approximately 15 and $49 \%$ higher, respectively, than those obtained by Nowicki et al. (4). This may relate to differences in the duration of the fast prior to the study and/or differences among groups of newborn piglets. Although the 30-min postprandial blood flow values did not significantly increase above baseline in this group due to the small number of animals and large variability, values were consistently 35-198\% above baseline at 15-30 min postprandial. These increases were confined primarily to the jejunal and ileal mucosal-submucosal tissues which are actively involved in nutrient absorption following a meal (23). Gallavan et al. (6) demonstrated in adult dogs a significant increase in blood flow to the proximal small intestine 30 and $90 \mathrm{~min}$ after feeding and to the distal small intestine 90 min after feeding. This appeared to be the time sequence for intestinal transit and exposure of different segments to the digested products of food. The increases in our study occurred at an earlier postprandial period (15-30 min following feeding) and are probably related to a faster gastric emptying rate (8) and intestinal transit time in the newborn piglet (24). We did not observe a postprandial increase in $\mathrm{O}_{2}$ extraction $(3,4)$ in our normoxemic-fed animals. This probably relates to a higher baseline $\mathrm{O}_{2}$ extraction in our piglets. We did confirm an increase in $\mathrm{O}_{2}$ delivery and uptake to meet the metabolic demands of digestion; however, our increases were mediated through increased blood flow localized primarily to the small intestine mucosa-submucosa. The changes in $\mathrm{O}_{2}$ transport in the neonatal GI tract represented here are for the entire GI tract rather than any particular GI region since portal venous blood does not adequately represent regional venous values $(4,15)$.

The HNF piglets showed unchanged total and regional GI blood flow during hypoxemia. This contrasts with reports $(8,9)$ in which ventilated newborn piglets showed significant reductions in GI blood flow during hypoxemia. The lack of significant reductions in GI blood flow observed in our study may relate to an improved ability of the spontaneously breathing animal to regulate GI blood flow $(25,26)$. During hypoxemia there were significant decreases in $\mathrm{O}_{2}$ delivery, however, the A- $\mathrm{V} \mathrm{O}_{2}$ difference was unchanged resulting in stable oxygen uptake with marked increases in $\mathrm{O}_{2}$ extraction. This is consistent with the metabolic theory of flow regulation which predicts that when basal oxygen availability-to-demand ratio is relatively high as in 
the neonatal intestine, adjustments in oxygen extraction will be the primary compensatory mechanism responsible for providing an adequate tissue $\mathrm{O}_{2}$ supply when oxygen availability-to-demand ratio is reduced (10). Oxygen extraction increases through dilatation of precapillary sphincters resulting in increased capillary surface area available for oxygen exchange (capillary recruitment) and/or capillary-to-cell $\mathrm{PO}_{2}$ gradient. This helps to maintain stable intestinal tract $\mathrm{O}_{2}$ uptake as seen in the newborn and fetal lamb $(10,15)$. In contrast to Edelstone's study in newborn lambs (10), newborn piglets increase intestinal oxygen extraction to compensate for decreased oxygen delivery when oxygen content was $\leq 6.5 \mathrm{ml} / \mathrm{dl}$. However, our study design did not allow us to determine a critical $\mathrm{CaO}_{2}$ or tissue $\mathrm{PO}_{2}$ below which compensation is no longer possible. Following termination of hypoxemia, there was recovery of GI blood flow to baseline values $(8,9)$. The recovery of flow appeared to be sustained in our study in contrast to data of Nowicki et al. (9) probably because of a lesser degree of hypoxemia, a better ability of spontaneously breathing animals to regulate GI blood flow, and/ or a higher baseline $\mathrm{GI} \mathrm{O}_{2}$ extraction and uptake.

The HF piglets did not exhibit a postprandial increase in GI blood flow, and total Gl blood flow was unchanged during hypoxemia. When regional flows were examined, stomach blood flow was reduced. The significance of this observation is uncertain. We could not determine gastric oxygen transport directly because gastric venous oxygen content data were unavailable; however, we assume that nutrients in the lumen would further increase oxygen demand and consumption (23) and decrease the oxygen availability-to-demand ratio within the tissues. According to the metabolic theory of blood flow regulation, this should cause the generation of a metabolic feedback signal which leads to a dilatation of both resistance vessels which regulate blood flow and precapillary sphincters which modulate $\mathrm{O}_{2}$ extraction (27). Also, we would expect a rise in blood flow due to the vasodilatory effect of chyme, GI hormones, or other blood-borne factors released in response to a meal $(5,23,28)$. How these factors vary and the degree of nutrient absorption and peristalsis in the fed intestinal tract during hypoxemia remain to be determined. Whether these functions are altered or diminished during hypoxia requires further investigation. We observed a marked increase in total $\mathrm{GI} \mathrm{O}_{2}$ extraction in the HF piglets which helped to maintain a stable $\mathrm{O}_{2}$ uptake during the hypoxemic insult. Following termination of hypoxemia, there was a sustained hyperemia. This reflects the ability of the GI tract to recover when the hypoxemic insult is ended and appears related to the increased oxygen demands of digestion, since similar degrees of posthypoxemic rebound hyperemia were not observed in HNF animals. This increased blood flow led to an increased trend of $\mathrm{O}_{2}$ uptake in the posthypoxemic period which was greater in the fed than in the HNF animals.

We conclude that feeding nonventilated hypoxemic newborn piglets results in unaltered total $\mathrm{GI}$ blood flow and a stable $\mathrm{O}_{2}$ uptake secondary to marked increases in $\mathrm{O}_{2}$ extraction when oxygen availability is reduced. Following limited exposure to hypoxemia, there is a significant hyperemia and an abiity to increase $\mathrm{O}_{2}$ uptake in an attempt to meet the demands of nutrient absorption. Oxygen uptake is not increased to the same extent as in normoxemic fed animals, thus the efficiency of these mechanisms in satisfying postprandial $\mathrm{O}_{2}$ demand remains to be determined.

Acknowledgment. The authors thank Ms. Donna Piva for her excellent technical assistance.

\section{REFERENCES}

1. Kosloske AM 1984 Pathogenesis and prevention of necrotizing enterocolitis: a hypothesis based on personal observation and a review of the literature. Pediatrics 74:1086-1092

2. Ostertag SG, LaGamma EF, Reisen CE, Ferrentino FL 1986 Early enteral feeding does not affect the incidence of necrotizing enterocolitis. Pediatrics 77:275-280

3. Edelstone DI, Holzman IR 1981 Gastrointestinal tract $\mathrm{O}_{2}$ uptake and regional blood flows during digestion in conscious newborn lambs. Am J Physiol 241:G289-G293

4. Nowicki PT, Stonestreet BS. Hansen NB, Yao AC, Oh W 1983 Gastrointestinal blood flow and oxygen consumption in awake newborn piglets: effect of feeding. Am J Physiol 245:G697-G702

5. Chou CC, Hsieh CP, Yu YM, Kvietys P, Yu LC, Pittman R, Dabney JM 1976 Localization of mesenteric hyperemia during digestion in dogs. Am J Physiol 230:583-589

6. Gallavan RH, Chou CC, Kvietys PR, Sit SP 1980 Regional blood flow during digestion in the conscious dog. Am J Physiol 238:H220-H225

7. Yu YM, Yu LCC, Chou CC 1975 Distribution of blood flow in the intestine with hypertonic glucose in the lumen. Surgery 78:520-525

8. Szabo JS, Stonestreet BS, Oh W 1985 Effects of hypoxemia on gastrointestinal blood flow and gastric emptying in the newborn piglet. Pediatr Res 19:466471

9. Nowicki PT, Miller RR, Hansen NB, Hayes JR 1985 Gastrointestinal blood flow and $\mathrm{O}_{2}$ uptake in piglets: recovery from hypoxemia. Pediatr Res 19:1197-1200

10. Edelstone DI, Lattanzi DR, Paulone ME, Holzman IR 1983 Neonatal intestinal oxygen consumption during arterial hypoxemia. Am J Physiol 244:G278G283

11. Heymann MA, Payne BD, Hoffman JIE, Rudolph AM 1977 Blood flow measurements with radionuclide-labelled particles. Prog Cardiovasc Dis 20:55-79

12. Bond JH, Prentiss RA, Levitt MD 1979 The effects of feeding on blood flow to the stomach, small bowel, and colon of the conscious dog. $J$ Lab Clin Med 93:594-599

13. Maxwell LC, Shepherd AP, Riedel GL, Morris MD 1981 Effect of microsphere size on apparent intramural distribution of intestinal blood flow. Am $\mathbf{J}$ Physiol 241:H408-H414

14. Maxwell LC, Shepherd AP, Riedel GL 1982 Vasodilation or altered perfusion pressure moves $15-\mu \mathrm{m}$ spheres trapped in the gut wall. Am J Physiol 243:H123-H127

15. Edelstone DI, Holzman IR 1982 Fetal intestinal oxygen consumption at various levels of oxygenation. Am J Physiol 242:H50-H54

16. Wallenstein S, Zucker CL, Fleiss JL 1980 Some statistical methods useful in circulation research. Circ Res 47:1-9

17. DeRoth L, Downie HG 1978 Basic cardiovascular parameters in the underweight neonatal swine. Biol Neonate $34: 155-160$

18. Kontos HA, Mauck HP, Richardson DW, Patterson JL 1965 Mechanism of circulatory response to systemic hypoxia in the anesthetized $\operatorname{dog}$. Am J Physiol 209:397-403

19. Fronek K, Stahlgren LH 1968 Systemic and regional hemodynamic changes during food intake and digestion in nonanesthetized dogs. Circ Res 23:687692

20. Chou CC, Kvietys P, Post J, Sit SP 1978 Constituents of chyme responsible for postprandial intestinal hyperemia. Am J Physiol 235:H677-H682

21. Pawlik WW, Fondacaro JD, Jacobson ED 1980 Metabolic hyperemia in canine gut. Am J Physiol 239:G12-G17

22. Dudgeon DL, Spoon D, Randall P 1981 The effects of gastric hyperosmotic glucose feedings on regional perfusion in the neonatal piglet. J Pediatr Surg 16:854-857

23. Gallavan RH, Chou CC 1985 Possible mechanisms for the initiation and maintenance of postprandial intestinal hyperemia. Am J Physiol 249:G301G308

24. Maner JH, Pond WG, Loosli JK, Lowrey RS 1962 Effect of isolated soybean protein and casein on the gastric $\mathrm{pH}$ and rate of passage of food residue in baby pigs. J Anim Sci 21:49-52

25. John E. McDevitt M, Cassady G 1983 Cardiac output and organ blood flow in young rabbits during intermittent positive-pressure ventilation. Biol Neonate 44:58-64

26. Furzan JA, Gabriele G, Wheeler JM, Fixler DE, Rosenfeld CR 1981 Regional blood flow in newborn lambs during endotracheal continuous airway pressure and continuous negative pressure breathing. Pediatr Res 15:874-878

27. Shepherd AP 1978 Intestinal $\mathrm{O}_{2}$ consumption and ${ }^{86} \mathrm{Rb}$ extraction during arterial hypoxia. Am J Physiol 234:E248-E251

28. Fara JW, Rubinstein EH, Sonnenschein RR 1972 Intestinal hormones in mesenteric vasodilation after intraduodenal agents. Am J Physiol 223:10581067 